\title{
SMOKING PRACTICES AND RISK AWARENESS IN PARENTS REGARDING PASSIVE SMOKE EXPOSURE OF THEIR PRESCHOOL CHILDREN: A CROSS-SECTIONAL STUDY IN TEHRAN
}

\author{
FARIDEH SHIVA, MOJGAN PADYAB
}

\section{ABSTRACT}

BACKGROUND: Young children living with parents who smoke are exposed to unacceptable health hazards. AIM: To determine patterns of parental smoking, the level of parental awareness about hazards of secondhand smoke, and the effect of risk awareness on smoking behavior. SETTNG: Health centers affiliated with two teaching hospitals in Tehran. DESIGN: Cross-sectional. MATERIALS AND METHODS: Data was collected from parents of preschool children visiting the health centers, through face-to-face interview, during a period of 18 months. STATISTICAL ANALYSIS: Data was analyzed by multiple logistic regression, and analysis of variance was done for comparison of means. RESULTS: In a total of 647 families, prevalence of parental smoking was $35.7 \%$, (231 families). In $97.8 \%$ of smoking families, only the fathers smoked; and in 5 (2.2\%) families, both parents were regular smokers. Prevalence of smoking was higher in poor families as compared with families who were well-off $(39 \%$ vs. $25 \% ; P=0.025)$, and also in families with lower educational level. There was no significant difference in risk awareness between smokers and nonsmokers $(P>.05)$. CONCLUSION: Low socioeconomic status and low education were identified as risk factors for children's exposure to secondhand smoke; parental risk awareness had no apparent effect on the smoking behavior. Unlike western societies, fathers were the sole habitual smokers in most families. Since factors that influence smoking behavior vary in different cultures, interventional strategies that aim to protect children from the hazards of tobacco smoke need to target diverse issues in different ethnic backgrounds.

Key words: Children, secondhand smoke, tobacco

\section{INTRODUCTION}

Tobacco smoke is a complex mixture of more than 4000 chemical compounds, including

Department of Pediatrics, Taleghani Medical Center, Shahid Beheshti Medical University, Tehran, Iran

\section{Correspondence:}

Dr. Farideh Shiva

Department of Pediatrics, Taleghani Medical Center,

Shahid Beheshti Medical University, Tehran,

Islamic Republic of Iran

E-mail: shivahfa@yahoo.com
43 known carcinogens, and cigarette use is a leading preventable cause of death in industrialized countries. ${ }^{[1-4]}$ Secondhand smoke (SHS) is a potentially preventable environmental pollutant linked with respiratory problems, and parental smoking has been associated with increased rates of sudden infant death syndrome, otitis media, asthma, and decreased lung growth. ${ }^{[3]}$

There is no safe level of exposure to 
secondhand smoke, as even low levels of exposure are associated with adverse health effects. Physicians caring for children need to discuss the harmful effects of smoking and the importance of reducing childhood exposure to secondhand smoke; parents should be educated and encouraged not to smoke; or if they are smokers, to quit. ${ }^{[5]}$

It has been observed that adopting the framework strategy of 5 A's (ask, advise, assess, assist, and arrange) gives each parent the maximum chance of quitting. ${ }^{\left[{ }^{[6]}\right.}$ However, before implementing an effective course of action, the counselor needs background knowledge about socio-demographic patterns and smoking habits of parents, as well as their attitudes towards the dangers of tobacco smoke. Questionnaires are relatively inexpensive and allow exposure assessment during different periods and in different indoor environments and hence are commonly used for assessing exposure to SHS in health-effects studies. ${ }^{[7]}$

We conducted this cross-sectional study to define smoking habits in parents of young children under the age of 5 years, to ascertain their knowledge of hazards that passive smoke creates for their offspring, and to see if risk awareness has any effect on their smoking behavior. Although smoking practices in different age groups have been appraised in quite a few research papers from Iran, we did not find another report from the region about the prevalence of smoking in parents of preschool children, in our literature search. ${ }^{[8-10]}$

Likewise, no research has addressed the issue of parental awareness about the adverse consequences of exposure to SHS in children and the effect of this insight on smoking behavior.

\section{MATERIALS AND METHODS}

\section{Setting}

Families of preschool children visiting health centers based in two teaching hospitals in the northern of Tehran during a period of 18 months, from July 2005 to December 2006, were recruited for this study.

\section{Inclusion criteria}

Families available to the study team during the study period with children between the ages of 3 months and 5 years were included in the study. Each family included the mother, father, and at least one child under the age of 5 years.

\section{Exclusion criteria}

Single-parent families were not enrolled. Parents of children with gross congenital anomalies or chronic illnesses and also parents with babies under the age of 3 months were excluded from the study.

Trained members of the study team interviewed the parents and recorded sociodemographic and other relevant data in a structured questionnaire. Data were collected consecutively from all subjects who met the enrollment criteria and who were available to the study team during the specified period.

\section{Variables}

Variables tested for comparison of the two groups (habitual smokers and nonsmokers), included the number of children; the sex of these children; parents' ages, education, and social status; and parents' awareness about the adverse effects of secondhand smoke (SHS) on their children. The effect of risk awareness on their smoking behavior was documented. In addition, child's birth weight, mode of delivery (normal or cesarean section), history of neonatal hospitalization, and duration of breastfeeding were recorded.

Socioeconomic status (SES) was graded according to the father's occupation: the families of directors, professionals, or business managers were placed in the 'high' social class; government employees and skilled workers, as well as students in 'intermediate' class, laborers, farmhands, and the unemployed made up the 'low' social class.

Risk awareness was graded as nil if parents thought that SHS was not harmful or did not know if it was unsafe for their children. If they knew that it was harmful to the respiratory system only, risk awareness was graded as positive; risk perception was considered high if parents responded with answers like 'secondhand smoke affects many systems including the heart, may cause death, is a poison, or a cause of cancer.'

\section{Analysis}

Families were divided into two groups on the basis of parental smoking behavior, i.e., smokers and nonsmokers. Smokers were then divided into two groups: those smoking outside the home and those who admitted to smoking indoors. A third grouping was made according to smoking status of parents: heavy smokers (10 or more cigarettes/day), moderate smokers (those who restrained their smoking habit to $<10$ cigarettes/ day or smoked occasionally), and nonsmokers.
SPSS software was used and data analyzed by multiple logistic regression. Analysis of variance (ANOVA) was done for comparison of means; Turkey test was used for multiple comparisons in people with different smoking status, i.e., heavy smokers, moderate smokers, and nonsmokers. The ' $\mathrm{t}$ ' test and 'independent samples' test were done for for comparison of data between smoker and non-smokers. Pearson chi-square was performed for all categorical data. A $P$ value of $<.05$ was considered significant. All variables were compared between the nonsmoking families and families of habitual smokers. Risk awareness was compared in all the three groups, i.e., smokers and nonsmokers; heavy smokers, moderate smokers, and nonsmokers; parents who smoked outdoors and those who smoked inside the home.

Details of the questionnaire were explained to all participants before obtaining their consen for the interview; all of them were agreeable for the interview since they felt that members of the study team were interested in their children's welfare.

No masking was done; both the parent and the interviewer were completely aware of the nature of the interview.

\section{RESULTS}

A total of 647 families were enrolled.

\section{Child characteristics}

The mean age of the children was 20.75 months. Three hundred twenty (49.5\%) children were females and $391(60.4 \%)$ were firstborn birth weight ranged from 1.3 to $4.8 \mathrm{~kg}$, mean 
birth weight being $3.17 \mathrm{~kg}$. Two hundred ninetyone (45\%) babies had been born through a cesarean section. Six hundred forty children were over 6 months of age at the time of enrollment, and $515(79.6 \%)$ of these had been on predominant breastfeeding for at least 6 months.

\section{Family characteristics}

At least one parent in 231 (35.7\%) families was a smoker; in all, except in 5 families, father was the sole smoker; and in 5 families, both parents smoked. A majority of smokers, i.e., 168 $(72.7 \%)$ habitual smokers, admitted to smoking indoors in the presence of their children. Out of the 203 smokers in whom smoking status had been recorded, 112 parents smoked more than 10 to 15 cigarettes/day and were classified as heavy smokers. The mean age of mothers and fathers was 27.6 and 32.2 years respectively; only 30 mothers were less than 20 years of age. The mean duration of education among mothers was 10.6 years; and among fathers, it was 11.6 years. One hundred nineteen (18.4\%) of all mothers were working mothers; the rest were housewives. Only 24 (3.7\%) parents were unaware that passive smoking was injurious

for their children, while $459(71 \%)$ parents were aware of the risk; and in the rest $(25.3 \%)$, risk perception was high - they believed secondhand smoke to be extremely dangerous for their children [Table 1].

Comparison of variables between the groups is given in Table 1.

Parent's educational status and the households SES were related to smoking [Table 1 and Figure 1].

In nonsmoking families, the mean educational level among fathers was 11.78 years, vs. 11.3 years in habitual smokers $(P>0.05)$. For mothers, the figures were 11.04 vs. 9.8 years $(P=0.03)$.

Table 1 shows the difference in SES between smoking and non-smoking households. Social status had been documented in 639 families. From the group of 409 nonsmokers, 81 (19.8 $\%)$ families belonged to high SES; and 328 $(80.2 \%)$ families, to the intermediate or low SES, as compared to the group of 230 habitual smokers, in which only $27(11.7 \%)$ families

Table 1: Characteristics of non-smoking and smoking households.

\begin{tabular}{lccc}
\hline Family particulars & Non-smoking families $n=416$ & Smoking families. $n=231$ & $P$-value \\
\hline Child's birth wt, kg. mean(SD) & 3.15 & 3.19 & 0.783 \\
Child's birth wt, $<2.5 \mathrm{~kg}$. (\%) & 4.3 & 6.9 & 0.1 \\
Cesarean Delivery (\%) & 51.2 & 33.8 & 0.000 \\
Male sex (\%) & 51 & 49.8 & 0.774 \\
First Child (\%) & 63.1 & 56.1 & 0.079 \\
Neonatal hospitalization (\%) & 16.7 & 11.7 & 0.089 \\
Full breast-feeding at 6 months (\%) & 79.3 & 82.5 & 0.492 \\
Mother's age, yrs. mean(SD) & $27.5(5)$ & $27.6(4.7)$ & 0.368 \\
Working mother (\%) & 21.4 & 13 & 0.008 \\
Mother's education, yrs. mean(SD) & $11.04(4.7)$ & $9.8(4.07)$ & 0.03 \\
Father's education, yrs. mean(SD) & $11.78(4.7)$ & $11.3(4.5)$ & 0.8 \\
SES* high $n=108(\%)$ & 11.7 & 0.01 \\
SES* Intermediate $\mathrm{n}=423(\%)$ & 19.8 & 71.7 & 0.03 \\
SES* low $n=108(\%)$ & 63.1 & 16.5 & 0.8. \\
$\%$ Risk awareness absent, $(\mathrm{n}=24)$ & 17.1 & 3.9 & 0.8 \\
\% Risk awareness present, $(\mathrm{n}=459)$ & 3.6 & 64.1 & 0.012 \\
$\%$ Risk awareness high, $(\mathrm{no}=164)$ & 74.8 & 32 & $>0.05$ \\
\hline
\end{tabular}

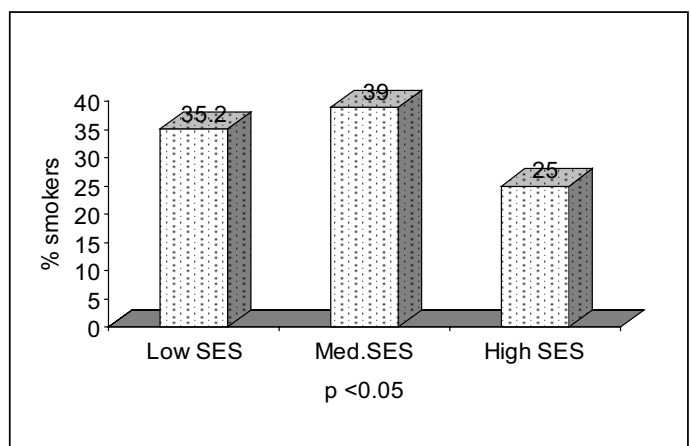

Figure 1: Frequency of smokers according to socioeconomic status (SES)

belonged to the high SES group ( $P=0.01$ ); and $203(88.2 \%)$ families, to the middle or low SES.

Figure 1 shows the prevalence of smokers in families with different SES, highlighting the fact that in families with high socioeconomic status, the percentage of smokers was significantly lower than in the families with middle and lower SES ( $P=.025$ in both instances).

Figure 2 reveals that parental awareness of the risks of SHS was not significantly different in outdoor and indoor smokers; on the contrary, more indoor than outdoor smokers belonged to

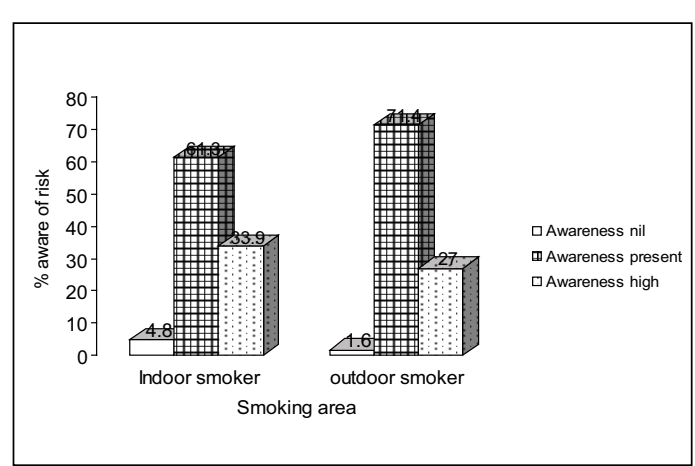

Figure 2: Comparison of risk awareness in indoor smoke and outdoor smokers the group of parents with high risk awarenes ( $33.9 \%$ vs. $27 \%$ respectively). Figure 3 compares risk awareness with respect to smoking status and defines clearly that there is no significan difference in risk awareness between smokers and nonsmokers, and between heavy smokers and moderate smokers; i.e., risk awarenes was high in $33.9 \%$ of heavy smokers, $34.1 \%$ of moderate smokers, and $21.1 \%$ of nonsmokers ( $P>0.05$ in all instances).

\section{DISCUSSION}

In our study, at least one parent was a smoke in more than $35 \%$ of the families. A survey of school children between 11 and 18 years of age from 20 provinces in Iran has shown the prevalence of self-reported cigarette smoking to be $14.3 \%$, with a higher prevalence in boys (18.5\%) than in girls (10.1\%). ${ }^{[8]}$ A study of 1095 students in Tehran, aged 14 to 18 years, reported that $29 \%$ smoked occasionally and $5 \%$ ( $6 \%$ of boys and $2 \%$ of girls) were daily smokers. ${ }^{[9]}$ According to statistical reports about 1 in 3 US children live with a smoker estimates of child exposure to secondhand smoke range from $25 \%$ to $43 \%$ of all children in the United States. ${ }^{[6,11]}$ Questionnaire-based

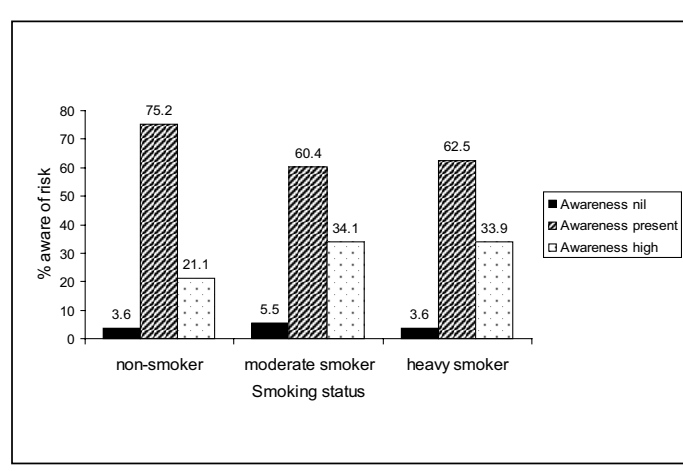

Figure 3: Comparison of risk awareness with respect to smoking status 
assessment of environmental tobacco smoke (ETS) exposure has varied from $7 \%$ in Finnish children to $>60 \%$ among Californian youth. ${ }^{[7]} \mathrm{A}$ survey in Greece revealed smoking prevalence among adults with preschool children to be $44 \%$ (52\% of fathers and $36 \%$ of mothers). ${ }^{[12]}$

Almost all smokers in our study were fathers ( $37 \%$ vs. $<3 \%$ mothers), which is contrary to reports from studies in western countries and Japan, where although fathers' smoking rates were higher, a significant number of mothers smoked as well, but is comparable to the situation in Taiwan, where the ratio of male-tofemale adult smokers was 11 to $1 . .^{[5,12-16]} \mathrm{A}$ recent global survey has estimated the prevalence of smoking in men to be $40 \%$ as compared to $12 \%$ in women. ${ }^{[17]}$

From Aleppo, the reported levels of parental smoking are $54 \%$ for men and $18 \%$ for women. ${ }^{[18]}$

\section{Strength of the study}

To identify the circumstances that predispose to parental smoking in normal family settings, we excluded families with stressful situations, like those having children with gross congenital anomalies or chronic illnesses. We chose to study parents of preschool children, since young children are unable to avoid exposure and their youth makes them vulnerable to parental role modeling; also, increased nicotine receptors in the brain due to smoke exposure have some bearing on increased rates of experimenting with cigarettes and smoking initiation in the children of habitual smokers. ${ }^{[3]}$

The major limitation of this study was that the smoking status was not checked using biomarkers of exposure, i.e., cotinine, but we relied on parents' information; however, studies have shown that parental self-report accurately captures ETS and is therefore valid and reliable. ${ }^{[13,19,20]}$

Reports suggest that smoking remains concentrated among the poor and less well educated, precisely the families who can least afford the financial burden. ${ }^{[6,13]}$ A study from Iran identified poverty as one of the most common reasons for cigarette smoking in young people. ${ }^{[10]}$ We observed that in our subjects, frequency of smoking parents was significantly lower in families with high social status in comparison to households with low socioeconomic circumstances.

The likelihood that a child will live with an adult smoker decreases as the education level of adults in the family increases. According to statistics, only about $25 \%$ of children living with an adult who had 13 or more years of education faced the issue of secondhand smoke at home, versus nearly $40 \%$ of children from families in which no adult had that much education. ${ }^{[11]}$ Two national surveys done in Norway stated that the level of parental education was a significant predictor; while in Greece, paternal education was related to smoking, but the level of maternal education was not. ${ }^{[12,21]}$ We found a positive association between higher maternal education and no smoking in the family; likelihood of smoking decreased with a higher level of paternal education as well, although the difference was not significant.

Some reports state that a significant number of parents remain unaware of the detrimental effects of smoking on their children's health; ${ }^{[6]}$ however, almost all subjects in our study were aware that passive smoking was harmful to their children, while $25 \%$ thought it was extremely harmful and may cause death. Studies have revealed that risk awareness seems to have insignificant effect on smoking behavior, a fact that was reiterated in our study as well. ${ }^{[21]}$ It seems that risk perception is not the prime factor that would curtail or stop habitual smokers from smoking in the presence of their children.

A prospective cohort study shows that maternal smoking has a negative effect on the initiation and duration of breast-feeding. ${ }^{[22]}$ In our study, the number of smoking mothers was very small, and fathers' smoking behavior did not affect the status of breast-feeding.

Since children who are exposed to smokers in their household are three times more likely to initiate smoking themselves, the number of potential smokers increases with increasing number of children in the family. ${ }^{[6]}$ In our study, there was no difference in the rate of smokers in families with one or more children. We did not find a comparative study during our literature search.

\section{Summary of key findings}

With our young children, the main problem is paternal smoking; mostly mothers do not smoke. Also, lower parental education and low socioeconomic conditions are risk factors for parental smoking. Despite risk awareness, fathers continue their smoking habits, revealing that a deeper insight than mere knowledge is needed to change ingrained behavior.

The interesting finding of the positive effect of maternal education on their spouses' smoking habits underscores the significance of female education in improving health consciousness in families. However, it is clear that a lack of maternal education is not the primary risk facto for exposure of children at home. To reduce exposure to secondhand smoke in young children and to understand the motivation behind risk-taking social behaviors, wellplanned nationwide surveys are needed.

\section{REFERENCES}

1. Gergen PJ. Environmental tobacco smoke exposure as a risk factor for respiratory disease in children. Respir Physiol 2001;128:39-46.

2. Cook DG, Strachan DP. Summary of effects of parental smoking on respiratory health of children and implications for research. Thorax 1999:54:357-66.

3. Winickoff JP, McMillen RC, Carroll BC, Klein JD, Rigotti NA, Tanski SE, et al. Addressing parental smoking in pediatrics and family practice: A national survey of parents. Pediatrics 2003;112:1146-51.

4. Centers for Disease Control and Prevention (CDC). Cigarette use among high school students-United States, 1991-2005. MMWR Morb Mortal Wkly Rep 2006;55:724-6.

5. Frankowski BL, Weaver SO, Secker-Walker RH. Advising parents to stop smoking: Pediatricians' and parents' attitudes. Pediatrics 1993;91:296 300.

6. Winickoff JP, Berkowitz AB, Brooks K, Tansk SE, Geller A, Thomson C, et al. State-of-the-art interventions for office-based parental tobacco control. Pediatrics 2005;115:750-60.

7. Gilmour MI, Jaakkola MS, London SJ, Nel AE, Rogers CA. How exposure to environmenta tobacco smoke, outdoor air pollutants and increased pollen burdens influences the incidence of asthma. Environ Health Perspect 2006;114: 627-33.

8. Kelishadi R, Ardalan G, Gheiratmand R, Majdzadeh 
R, Delavari A, Heshmat R, et al. Smoking behavior and its influencing factors in a nationalrepresentative sample of Iranian adolescents: CASPIAN study. Prev Med 2006;42:423-6.

9. Heydari G, Sharifi H, Hosseini M, Masjedi MR. Prevalence of smoking among high-school students of Tehran in 2003. East Mediterr Health J 2007;13:1017-21.

10. Kelishadi R, Mokhtari MR, Tavasoli AA, Khosravi A, Ahangar-Nazari I, Sabet B, et al. Determinants of tobacco use among youths in Isfahan, Iran. Int J Public Health 2007;52:173-9.

11. One in 3 US children lives with at least 1 adult smoker. Agency for Healthcare Research and Quality (AHRQ) Medscape Business of Medicine 2007. Available from: http://hcup.ahrq.gov/ HCUPnet.asp.

12. Vardavas $\mathrm{Cl}$, Athanasopoulos D, Balomenaki E, Niaounaki D, Linardakis MK, Kafatos AG. Smoking habits of Greek preschool children's parents. BMC Public Health 2007;7:112.

13. Cornelius MD, Goldschmidt L, Dempsey DA. Environmental tobacco exposure in low-income 6-year-olds: Parent report and urine cotinine measures. Nicotine Tob Res 2003;5:333-9.

14. Dilpisheh A, Kelly Y, Brabin BJ. Passive cigarette smoke exposure in primary school children in Liverpool. Public Health 2006;120:65-9.

15. Wen CP, Levy DT, Yuan Cheng T, Hsu CC, Tsai SP. Smoking behavior in Taiwan, 2001. Tobacco Control 2005;14:51-5.

16. Kaneita Y, Yokoyama E, Miyake T, Harano S, Asai T, Tsutsui T, et al. Epidemiological study on passive smoking among Japanese infants and smoking behavior of their respective parents: A nationwide cross-sectional survey. Prev Med 2006;42:210-7.

17. Wipfli $H$, Avila-Tang E, Navas-Acien A, Kim S, Onicescu G, Yuan J, et al. Secondhand smoke exposure among women and children: Evidence from 31 countries. Am J Pub Health 2008;98:672-9.

18. Maziak W, Tabbah K. Smoking among adults in Syria: Proxy reporting by 13-14 year olds. Public Health 2005;119:578-81.

19. Emerson JA, Howell MF, Metzer SB, Zakarian JM, Hoffsetter CR, Wahlgren DR, et al. The accuracy of environmental tobacco exposure measures among asthmatic children. J Clin Epidemiol 1995;48:1251-9.

20. Soliman S, Pollack HA, Warner KE. Decrease in the prevalence of environmental tobacco smoke exposure in the home during the 1990s in families with children. Am J Public Health 2004;94: 314-20.

21. Rise J, Lund KE. Predicting children's level of exposure to environmental tobacco smoke based on two national surveys in Norway in 1995 and 2001. Addict Behav 2005;30:1267-71.

22. Di Napoli A, Di Lallo D, Pezzotti P, Forastiere F, Porta D. Effects of parental smoking and level of education on initiation and duration of breastfeeding. Acta Paediatr 2006;95:678-85.

Source of Support: Nil

Conflict of Interest: None declared. 